\title{
Carbon Sequestration Potential in a Ten Year Old Oil Palm under Irrigated Conditions
}

\author{
M. Kiran Kumar ${ }^{1,2}$, Rajasekhar Pinnamaneni ${ }^{3,4}$, T. Vijaya Lakshmi ${ }^{2}$ and K. Suresh ${ }^{1}$ \\ ${ }^{1}$ ICAR-Indian Institute of Oil Palm Research, Pedavegi-534 450, A.P., India \\ ${ }^{2}$ Department of Environmental Sciences, Jawaharlal Nehru Technological University Hyderabad, \\ Hyderabad-500 085, India \\ ${ }^{3}$ Department of Biotechnology, Sreenidhi Institute of Science and Technology, \\ Yamnampet, Ghatkesar, Hyderabad-501 301, India \\ ${ }^{4}$ Department of Biotechnology, K L University, Greenfields, Vaddeswaram, \\ Guntur District-522 502, A.P., India \\ *Corresponding author
}

A B S T R A C T

\begin{abstract}
Keywords
Carbon sequestration, Oil palm, Irrigated conditions.

Article Info

Accepted:

17 June 2017

Available Online:

10 August 2017

Terrestrial ecosystems play a vital role in regulating greenhouse gas balance of crop production given the need to minimize the emissions associated with global warming and climate change. Such emissions can be minimized by growing perennial crops such as oil palm to enhance the buildup of terrestrial carbon pool. Carbon sequestration in a ten year old mature oil palm plantation was taken up for the study by destructive analysis. Among different plant parts, trunk biomass contributed to $50.9 \mathrm{~T}^{\mathrm{T}} \mathrm{ha}^{-1}$, while leaves and roots accumulated 19.3 and $2.20 \mathrm{~T}^{-h^{-1}}$ respectively. The carbon sequestered by the adult oil palm was 29.7 T.ha ${ }^{-1}$. This present investigation would be useful for developing a comprehensive and accurate database regarding the carbon storage in a ten year old oil palm under irrigated conditions and also quantify the carbon sequestration potential by oil palm plantations and explore its potential in mitigating global climate change.
\end{abstract}

\section{Introduction}

Oil palm is the fastest growing component of Indian vegetable oil sector giving 4-6 tonnes of oil/ha. Recognizing the scope of this crop in India under irrigated conditions, potential areas at present oil palm is grown in India to an extent of 2.62 lakh ha with productivity levels reaching as high as 30-35 $\mathrm{t}$ FFB/ha/year. Out of 15 states of oil palm grown areas, Andhra Pradesh leads the forefront in terms of area and productivity. It is a humid tropical crop which requires rainfall of 2000-3000 mm per annum with monthly minimum and maximum temperature range of $22-24^{\circ} \mathrm{C}$ and $29-33^{\circ} \mathrm{C}$. The higher concentration of green house gases (GHG) in the atmosphere, particularly $\mathrm{CO}_{2}$, which is responsible for $50 \%$ of the overall GHG effect (Bergonzini, 2004) and its average concentration increased from 290 to $380 \mathrm{ppm}$ from 19th to 20th century. Capturing of atmospheric carbon (C) and storing it in the terrestrial biosphere is one of the options, for 
mitigation of GHG reduction. The input of carbon into the plant is first determined by the rate of photosynthesis and the metabolic reactions that convert carbohydrates to plant biomass and maintain the standing biomass. Oil palm has major potential for atmospheric $\mathrm{CO}_{2}$ sequestration and is used for judging the environmental impacts of this perennial crop (Lamade and Bouillet, 2005). It not only helps in reduction of $\mathrm{CO}_{2}$ from atmosphere but also increases its sequestration, which enhances quality of soil, air and wildlife habitat. Based on the eddy covariance technique by Henson (1989), the annual uptake of $\mathrm{CO}_{2}$ by mature oil palm on coastal soil in Malaysia was 46.4 $\mathrm{T} \mathrm{ha}^{-1} \mathrm{yr}^{-1}$ with a net fixation of about $11.0 \mathrm{~T}$ $\mathrm{ha}^{-1}$.

Clean development mechanism was also created as a part of the Kyoto protocol in 1997 to lower cost involved in reducing GHG emissions released to the atmosphere and to support sustainable development initiatives with-in the developing countries like India. Terrestrial carbon sequestration is the carbonstorage approach which can be attained by planting perennial crops like oil palm to mitigate climate change and achieve enhanced terrestrial carbon pool. Enhanced biological storage of carbon has the potential to reduce atmospheric $\mathrm{CO}_{2}$ considerably (Winjum et al., 1992; Mutuo et al., 2005). The carbon capture and storage technologies provide a potentially valuable set of tools for achieving the magnitude of emissions reduction required for $\mathrm{CO}_{2}$ stabilization. Lenton and Huntingford (2003) reported that the biosphere may soon become a net source rather than a net sink of atmospheric carbon due to changes in climate. Unsustainable practices like deforestation, causing damage to wild life, unprecedented use of fertilizers and pesticides cause environmental damage in terms of increased carbon emission and therby global warming, disturbance to biodiversity with a severe impact on planet earth. The direct method for measurement of carbon stocks accumulated by a plant is by weighing plant samples for annual or perennial plants by measuring specific parameters like diameter, height, wood density etc. This paper examines the changes in total biomass and carbon storage content among different plant parts of oil palm by destructive sampling.

\section{Materials and Methods}

The study was conducted at Directorate of Oil Palm Research, Pedavegi and is situated in West Godavari district, Andhra Pradesh, India which was located at $16^{\circ} 8^{\prime} \mathrm{N}, 81^{\circ} 11^{\prime} \mathrm{E}$, with a mean sea level of $13.4 \mathrm{~m}$. The palms were planted with $9 \mathrm{~m}$ triangular spacing and standard agronomic practices were followed (Berthaud et al., 2000). Two palm trees grown under uniform management conditions (Fig. 1) were uprooted and plant parts were separated. Fresh weights of trunk, leaflets, rachis, spears and roots were taken and their representative samples were dried in hot air oven at $65^{\circ} \mathrm{C}$ to attain constant weight and dry weights were taken. The samples are ground by $0.2 \mathrm{~mm}$ sieve for analyzing the total carbon (Syahrinudin, 2005). The estimation of carbon contents in the different samples were done on the basis of dry combustion, with the help of CHNS analyzer (Vario EL III, Elementar, Germany). The total carbon of the systems was calculated based on the carbon component and mass of each component of the system.

\section{Results and Discussion}

Among different plant parts, trunk biomass contributed to $50.9 \mathrm{~T}^{\mathrm{T}} \mathrm{ha}^{-1}$, while leaves and roots accumulated 19.3 and $2.20 \mathrm{~T}^{\mathrm{ha}}{ }^{-1}$ respectively (Table 1$)$. 
Table.1 Above and below ground biomass $\left(\mathrm{T} \mathrm{ha}^{-1}\right)$ and carbon sequestered $\left(\mathrm{T} \mathrm{C}^{-h^{-1}}\right)^{\text {by }}$ different plant parts in a ten year palm grown under irrigated conditions (Mean \pm SD)

\begin{tabular}{lllll}
\hline ant part & $\begin{array}{l}\text { Biomass } \\
\left(\mathrm{kg} \mathrm{palm}^{-1}\right)\end{array}$ & $\begin{array}{l}\text { Biomass } \\
\left(\mathrm{T} . h a^{-1}\right)\end{array}$ & $\begin{array}{l}\text { Carbon sequestered } \\
\left(\mathrm{kg} \mathrm{palm}^{-1}\right)\end{array}$ & $\begin{array}{l}\text { Carbon sequestered } \\
\left({\left.\mathrm{T} \mathrm{C} . \mathrm{ha}^{-1}\right)}^{\mathrm{P}}\right)\end{array}$ \\
\hline Leaf & $135.5 \pm 36.1$ & $19.3 \pm 5.2$ & $50.1 \pm 13.4$ & $7.1 \pm 1.9$ \\
Trunk & $356.5 \pm 68.6$ & $50.9 \pm 9.8$ & $153.5 \pm 29.1$ & $21.9 \pm 4.2$ \\
Roots & $15.42 \pm 2.2$ & $2.20 \pm 0.3$ & $7.52 \pm 0.6$ & $1.07 \pm 0.1$ \\
Total & $507.12 \pm 34.6$ & $72.5 \pm 5.0$ & $208.3 \pm 16.3$ & $29.7 \pm 2.3$ \\
\hline
\end{tabular}

Fig.1 Ten year old oil palm selected for destructive analysis under irrigation conditions

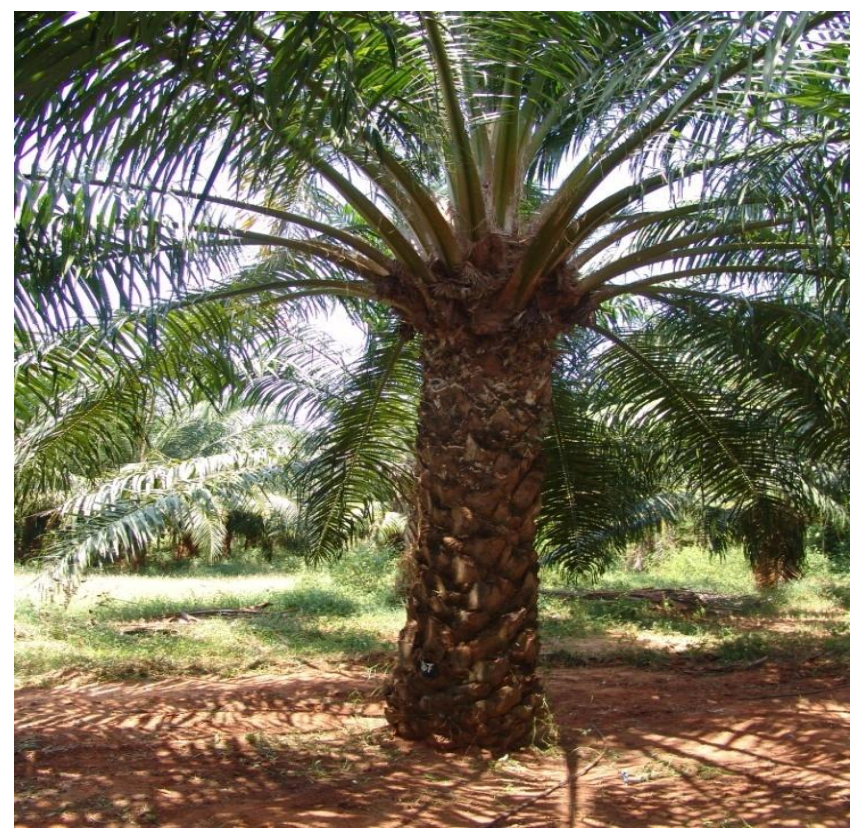

Fig.2 Oil palm showing root biomass around the palm base

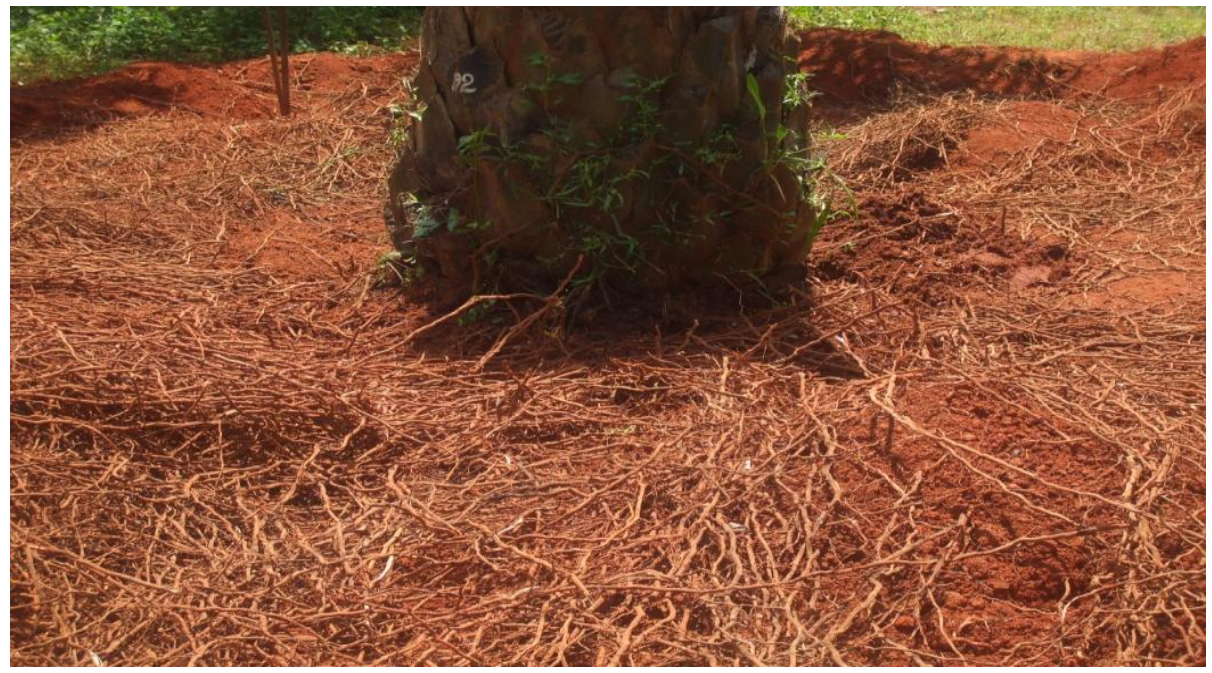


Oil palm produces large quantities of dry matter mainly due to larger surface area, complete ground cover by the whole year resulting in higher light interception and total dry matter production (Rees, 1962) compared to annual crops. The standing biomass in a adult indicated higher biomass content in trunk followed by leaf and roots under both irrigated rainfed conditions (Suresh and Kiran, 2011). Dufrene (1989) observed that the above ground biomass accumulation in trunk was about $40 \mathrm{~T}$ dry matter $\mathrm{ha}^{-1}$ or more in palms older than 20 years and found a total root biomass of $31.5 \mathrm{~T} \mathrm{ha}^{-1}$ for 10 year old palms in Ivory coast, where as Lamade and Setiyo (1996) found only $14.1 \mathrm{~T} \mathrm{ha}^{-1}$ and 9.7 $\mathrm{T} \mathrm{ha}^{-1}$ of two families in Indonesia. Root biomass is more difficult to estimate and its measurement requires destructive sampling (Fahmuddin et al., 2009). Differences in root biomass in different areas were obtained according to different soil types. $89 \%$ of carbon losses from atmosphere are mainly because of loss of living biomass of total carbon stored in both vegetation and soil (Houghton, 2005). The results conform to the findings of Hartley (1988) that most of the roots are concentrated around the palm base and within $0.5 \mathrm{~m}$ from the ground (Fig. 2).

Among different plant parts, trunk sequestered $21.9 \mathrm{~T} \mathrm{C}^{\mathrm{T}} \mathrm{ha}^{-1}$, while leaves and roots sequestered 7.16 and $1.07 \mathrm{~T}$ C.ha ${ }^{-1}$ respectively. The total carbon sequestered by a ten year adult oil palm was 29.7 T.ha $^{-1}$ (Table 1). The amount of $\mathrm{C}$ sequestered was more in trunk followed by leaves and roots and confirm to the findings of Suresh et al., (2008) who reported carbon sequestration of 17.98 - 35.44 T C.ha ${ }^{-1}$. The carbon contents were found to be low in younger leaves and higher in older leaves. Syahrinudin (2005) reported that biomass $\mathrm{C}$ of oil palm system in Indonesia increased persistently with plantation age and ranged from 16.6 to 84.6

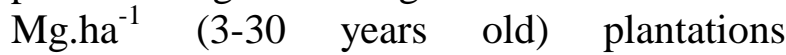

respectively. Carbon storage in the biomass elaborates each year primarily with the age and secondarily on agro-ecological conditions. Loss of standing biomass may be offset by long-term carbon storage, either as harvested material or carbon sequestered in soil organic matter. The total amount and proportion of $\mathrm{C}$ storage varies depending on soil fertility, climate, and land use types (Fahmuddin et al., 2009).

To conclude, standing perennial crops like oil palm serve as net accumulators of carbon, thereby offsetting carbon emissions, arising from the consumption of fossil fuels and also help in financial gains through carbon trading under the Kyoto Protocol. The expansion of oil palm plantations may represent a carbon debit if practice is to replace the tropical forest by this crop (Fargione et al., 2008). It also seems to be a prime candidate for storing carbon in which oil palm is grown and is eligible for the clean development mechanism. The present investigation would be useful for developing a comprehensive and accurate database regarding the carbon storage in oil palm plantation under irrigated conditions and also quantify the carbon sequestration potential by oil palm plantations and explore its potential in mitigating global climate change.

\section{References}

Bergonzini, J.C. 2004. Changements climatiques, désertification, diversité biologique, et forets. Riat: Silva, p.146.

Berthaud, A., Nunes, C.D.M., Barcelos, E. and Cunha, R.N.V. 2000. Implantação e exploração da cultura do dendezeiro. In: Viégas, I.J.M., Muller, A.A., editors. A cultura do dendezeiro na Amazônia Brasileira. Belém: Embrapa Amazônia Oriental \& Manaus: Embrapa Amazônia Ocidental. 
Dufrene, E. 1989. Photosynthese consummation en eauet modelisaton de la production chez le palmier a huile (Elaeis guineensis Jacq. ). These de Docteur en Sciences, Universite ParisSud Orsay, pp. 154.

Emmanuelle Lamade and Jean-Pierre Bouillet. 2005. Carbon storage and global change: the role of oil palm. Dossier, vol. 12: 154-160.

Fahmuddin Agus, Eleonora Runtunuwu, Tania June, Erni Susanti, Herna Komara, Haris Syahbuddin, Irsal Las and Meine van Noordwijk. 2009. Carbon dioxide emission in land use transitions to plantation. Jurnal Litbang Pertanian, 28(4): 119-126.

Fargione, J., Hill, J., Tilman, D., Polasky, S. and Hawthorne, P. 2008. Land clearing and the biofuel carbon debt. Sci., 319: 1235-1238.

Henson, I.E. 1989. Report of PORIM workshop on productivity of oil palm. ISOPB Newslett., 6: 2-4.

Hartley, C.W.S. 1988. The Oil Palm (Third Edition) Longman Group UK Limited. P. 761

Houghton, R.A. 2005. Aboveground forest biomass and the global carbon balance. Global Change Biol., 11: 945-958.

Lenton, T. and Huntingford, C. 2003. Global terrestrial carbon storage and uncertainties in its temperature sensitivity examined with a simple model. Global Change Biol., 9(10): 1333-1352.

Lamade, E. and Setiyo, I.E. 1996. Test of Dufrene's production model of two contrasting fmilies of oil palm in North
Sumatra. In. Proc. 1996 PORIM Int. Palm Oil Congress 'Competitiveness for the $21^{\text {st }}$ centuary' (Ed. D. Ariffin et al.,) Palm Oil Res. Inst., Malaysia, Kuala Lampur, pp. 427-435.

Mutuo, P., Cadisch, G., Albrecht, A., Palm, C. and Verchot, L. 2005. Potential of agroforestry for carbon sequestration and mitigation of greenhouse gas emissions from soils in the tropics. Nutrient Cycling in Agroecosystems, 71(1): 43-54.

Rees, A.R. 1962. Dry matter production of evergreen perennials. Nature, 195: 1118-1119.

Syahrinudin. 2005. The potential of oil palm and forest plantations for carbon sequestration on degraded land in Indonesia. Ecol. Develop. Series, 28: 1107.

Suresh, K., Reddy, V.M. and Kochu Babu, M. 2008. Biomass, carbon and nitrogen distribution with leaf age in oil palm. Poster presented in the third Indian Horticultural Congress held at Bhubaneswar during $6^{\text {th }}$ to $9^{\text {th }}$ Nov, 2008.

Suresh, K. and Kiran Kumar, M. 2011. Carbon sequestration potential of oil palm under irrigated and rainfed conditions. Indian J. Dry Land Agri. Res \& Dev., 26(2): 55-57.

Winjum, J., Dixon, R. and Schroeder, P. 1992. Estimating the global potential of forest and agroforest management practices to sequester carbon. Water, Air, and Soil Pollution, 64(1-2): 213227.

\section{How to cite this article:}

Kiran Kumar, M., Rajasekhar Pinnamaneni, T. Vijaya Lakshmi and Suresh, K. 2017. Carbon Sequestration Potential in a Ten Year Old Oil Palm under Irrigated Conditions. Int.J.Curr.Microbiol.App.Sci. 6(8): 1339-1343. doi: https://doi.org/10.20546/ijcmas.2017.608.163 